\title{
Application of antibody phage display to identify potential antigenic neural precursor cell proteins
}

\author{
Ioannis Paspaltsis ${ }^{1,2}$, Evangelia Kesidou ${ }^{2}$, Olga Touloumi ${ }^{2}$, Roza Lagoudaki ${ }^{3}$, Marina Boziki ${ }^{2}$, Martina Samiotaki ${ }^{4}$, \\ Dimitra Dafou ${ }^{5}$, Theodoros Sklaviadis ${ }^{1}$ and Nikolaos Grigoriadis ${ }^{2^{*}}$
}

\begin{abstract}
Background: The discovery of neural precursor cells (NPCs) and the concomitant intensive research in the field offer regenerative medicine novel approaches, enabling it to tackle conditions, such as neurodegenerative diseases. Transplantation of NPCs is nowadays considered a cutting-edge treatment for these conditions and many related clinical trials have been already completed or are still ongoing. However, little is known about the antigenicity of NPCs, with most studies addressing the question whether their antigenicity could lead to rejection of the transplanted cells.

Results: In this study we investigated the antigenic potential of syngeneic NPCs emulsion, upon subcutaneous (s.c.) administration to wild type C57BL/6 mice, following a standard immunization protocol. The whole lgG repertoire expressed upon immunization was cloned into a Fab phage display vector. From the created phage display library, Fab expressing clones interacting with NPCs lysate proteins were selected with the biopanning technique. The lgG Fab fragment from clone 65 proved to be reactive against antigens originating from NPCs lysates and/or whole brain lysate in diverse immunological assays.

Conclusions: Using a standard immunization protocol to administer NPCs antigens, and applying the Fab fragment phage display technique, we were able to isolate at least a monoclonal lgG Fab fragment, which interacts with different mouse brain proteins. It is not clear whether such antibodies are produced in the host organisms, following NPCs transplantation.
\end{abstract}

Keywords: Neural precursor cells, NPCs, Recombinant Fab fragments, Antibody phage display

\section{Background}

Neural precursor cells (NPCs) are multipotent, selfrenewing, ectoderm-derived progenitor cells, which support brain tissue homeostasis. Depending on the needs in health or disease, NPCs may differentiate into neurons, astrocytes and oligodendrocytes or they can release soluble factors, which regulate brain functions. In

\footnotetext{
*Correspondence: ngrigoriadis@auth.gr

${ }^{2}$ B' Department of Neurology, AHEPA General University Hospital of Thessaloniki, Aristotle University of Thessaloniki, 54636 Thessaloniki, Greece

Full list of author information is available at the end of the article
}

the mammalian brain, NPCs are found in niches mainly located in the dentate gyrus of the hippocampus, the lateral subventricular zone (SVZ) and the olfactory bulb [1, 2].

Isolated NPCs can be cultured in vitro as single cell suspensions. In the presence of EGF and/or FGF2 these suspensions grow into neurospheres. Clustered single cells forming a neurosphere may in turn be enzymatically dissociated and either recultured to produce new neurospheres or used for experimental and therapeutic purposes [2, 3]. As reported, human spinal cord-derived NPCs could retain their initial multipotency even after 18

c) The Author(s) 2020. This article is licensed under a Creative Commons Attribution 4.0 International License, which permits use, sharing, adaptation, distribution and reproduction in any medium or format, as long as you give appropriate credit to the original author(s) and the source, provide a link to the Creative Commons licence, and indicate if changes were made. The images or other third party material in this article are included in the article's Creative Commons licence, unless indicated otherwise in a credit line to the material. If material is not included in the article's Creative Commons licence and your intended use is not permitted by statutory regulation or exceeds the permitted use, you will need to obtain permission directly from the copyright holder. To view a copy of this licence, visit http://creativeco mmons.org/licenses/by/4.0/. The Creative Commons Public Domain Dedication waiver (http://creativecommons.org/publicdomain/ zero/1.0/) applies to the data made available in this article, unless otherwise stated in a credit line to the data. 
such passages and could be successfully transplanted into immunodeficient rats [4].

Transplantation of NPCs is considered a promising therapeutic intervention against disorders affecting the central nervous system (CNS), including neurodegenerative diseases. In fact, many clinical trials assessing the therapeutic potential of NPCs transplantation are still ongoing or have been completed [3,5]. It has been suggested that the therapeutic effects observed after NPCs transplantation occur as a result of their chemotactic migration towards the lesion and in dependence on the disease-produced specific cytokines [6].

The origin of the graft and its immunogenic potential need to be carefully considered when selecting the most suitable graft for transplantation. In this way, adverse reactions are minimized and graft rejection is avoided. In this regard, autologous or syngeneic grafts are considered as safer, since they are rarely rejected, while transplantation of allogeneic grafts is usually associated with higher rejection rates of the donor material $[7,8]$. Hence, research on the immunogenicity of transplanted NPCs is primarily focused on whether immune system activation may affect the survival of the transplanted cells and aims at developing strategies to increase the percentage of surviving NPCs following transplantation. On the other hand, the potential of transplanted syngeneic NPCs to trigger humoral immune responses of the host organism remains, to our knowledge, is barely investigated.

In the current study we immunized C57BL/6 mice with syngeneic neurosphere-derived NPCs and cloned the whole IgG repertoire in a Fab phage display library. Phage clones displaying monoclonal Fab fragments on their surface were isolated based on their immunoreactivity against the whole NPCs proteome. Fab sequences were analyzed, recombinant monoclonal Fab fragments were expressed in Escherichia coli cells and their reactivity to NPCs lysates was tested. One of the selected clones (clone 65) was able to immunoprecipitate diverse antigens derived from a mouse whole brain lysate. These data suggest that syngeneic NPCs may trigger immune responses resulting in antibody production. Further studies are required to determine whether such antibodies are produced following NPCs transplantation and to delineate the effects of produced antibodies in the context of disease conditions, where NPCs transplantation is performed.

\section{Results}

Immunization

Antisera harvested from the two immunized mice (serum 1 and 2) were tested for immunoreactivity against proteins from NPCs lysates by immunoblotting. When equally diluted (1:1000), serum 2 displayed stronger reactivity, compared to serum 1 . Figure 1 shows NPCsassociated protein bands, recognized by serum 2 . The pre-immune serum, in comparison, displays markedly reduced immunoreactivity.

\section{Library complexity-clone enrichment by biopanning}

Escherichia coli XL1-Blue cells were transformed with the phagemid containing DNA coding for the Fab fragments and the transformants were titrated to estimate the size of the library. Titration results showed that the created unamplified phage library consisted of $2.5 \times 10^{6}$ plaque forming units (pfu). Titration of input and output phage at each biopanning round are shown on Table 1.

\section{Sequencing results}

More than 20 individual Fab-expressing clones were isolated and the DNA encoding for the Fab was sequenced. Although no clone predomination was observed, two clones were isolated twice. Among the isolated clones, we focused on the recombinant Fab fragment from clone 65 because: (i) we were able to produce it in ample amounts

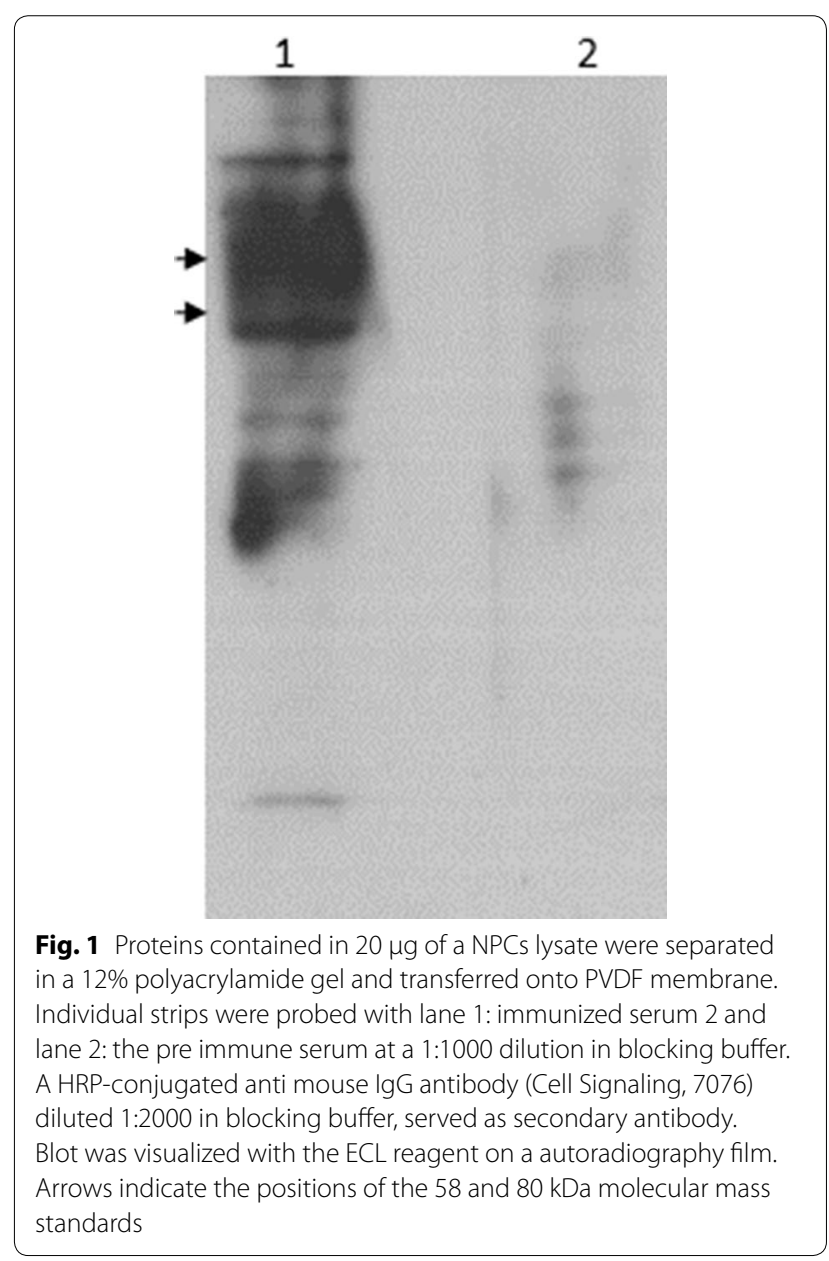


Table 1 Titration results after each biopanning round

\begin{tabular}{llllll}
\hline Panning round & Phage input (pfu) & \% & Phage output (pfu) $)^{\mathbf{b}}$ & $\begin{array}{l}\text { Enrichment } \\
\text { factor }^{\mathbf{d}}\end{array}$ \\
\hline 1 & $9.5 \times 10^{11}$ & $1.20 \times 10^{6}$ & $1.20 \times 10^{-6}$ & - \\
2 & $7.3 \times 10^{11}$ & $0.80 \times 10^{6}$ & $1.00 \times 10^{-6}$ & \\
3 & $2.0 \times 10^{11}$ & $8.48 \times 10^{7}$ & $4.24 \times 10^{-4}$ & 0.83 \\
\hline
\end{tabular}

a Number of phage pfu incubated with the antigens immobilized on the nitrocellulose strip

b Number of phage pfu eluted after the incubation above

c Percentage of bound phage calculated as the ratio phage output/phage input $\times 100$

$d$ Ratio of the percentage of bound phage at round $n$ vs the percentage of bound phage at round $n-1$

in E. coli cells, (ii) it was reactive against NPCs-derived antigens in western blot (Fig. 3b). The primary amino acid sequences of Fab 65 containing the complementarity determining regions (CDRs) from both heavy and light chain are shown in Fig. 2 . Of note, the variable heavy chain domain $\left(\mathrm{V}_{\mathrm{H}}\right)$ of clone 65 appeared in four additional Fab clones, combined with different light chains.

\section{Fab expression and immunoblot reactivity}

The recombinant Fab fragments were expressed in E. coli Top $10 F^{\circ}$ cells. The yield varied greatly among the different clones, with some clones producing extremely low amounts of pure Fab's, while others, including clone 65 , generating adequate for further analysis amounts. Figure 3a shows a representative picture of purified Fab 65. Following SDS-PAGE electrophoresis, samples from three elution fractions were stained with coomassie brilliant blue. Electrophoresis was carried out under non reducing conditions, i.e. in the absence of $\beta$-mercaptoethanol in the sample buffer. Under these conditions, the expected relative molecular mass of the Fab fragment is about $50 \mathrm{kDa}$. In the presence of $\beta$-mercaptoethanol, the assembled heavy and light chains of the Fab fragment, are resolved into two bands of about 32 and $25 \mathrm{kDa}$, respectively. The yield of Fab 65 purification under the conditions described in the methods section was approximately $1.0 \mathrm{mg} \mathrm{l}^{-1}$ of bacterial culture.

Reactivity of crude extracts from Fab fragment preparations or of purified Fab fragments was assessed by immunoblotting. Both preparations gave similar results, however signals acquired when crude extracts were used were more intense. Fab 65 was shown to recognize not one distinct but several antigens in protein lysates from mouse NPCs or CNS (Fig. 3b, lanes 1-2). Control strips were probed with a human Fab TT, which recognizes the unrelated tetanus toxin (provided by the Carlos F. Barbas III laboratory [9], Fig. 3b, lanes $3-4)$, or only with the secondary anti-mouse antibody (Fig. 3b, lanes 5-6). The intense bands at 25 and $50 \mathrm{kDa}$ in lanes 2, 4 and 6 correspond to the endogenous light and heavy chains from immunoglobulins of the spinal cord tissue.

\section{Immunohistochemistry-Immunofluorescence}

To further characterize immunoreactivity of the generated Fab fragments, we used them as primary antibodies in immunohistochemical (IHC) staining of mouse brain and spinal cord sections. To confirm signal-specificity, we used control sections in which only the secondary antibody was added. Cells expressing antigens recognized by the Fab's are stained brown, whereas cell nuclei are counterstained blue by hematoxylin staining. In agreement with the immunoblotting experiments, the monoclonal Fab fragment from clone 65 produced stronger and more specific signals, compared to other isolated Fab's.

Positive reacting cells were identified in all brain regions tested, namely the olfactory bulb, the subventricular zone with the rostral migratory stream, the striatum, the subgranular zone of the dentate gyrus, the cerebellum, as well as the white matter of the spinal cord (Fig. 4).

Double immunofluorescence (dIF) was conducted in order to determine the cellular localization of the IHCpositive cells. Thus, mouse brain sections were probed with both Fab 65 crude extracts and either a commercial GFAP or a Nogo A antibody. As shown in Fig. 5, signal colocalization between Fab 65 and the anti-GFAP antibody occurred only in astrocytes of the olfactory bulb at a ratio of $\sim 17 \%$. No colocalization was observed in the other brain regions tested (the rostral migratory stream of the SVZ, the subgranular zone of the dentate gyrus, and the white matter of the spinal cord). When sections were double-stained with Fab 65 and the antiNogo A antibody, double staining was more prominent in oligodendrocytes (Fig. 5). Results from the dIFs are summarized in Additional file 1. Interestingly, there is no relevant signal colocalization observed on cells in the subgranular zone of the dentate gyrus. 


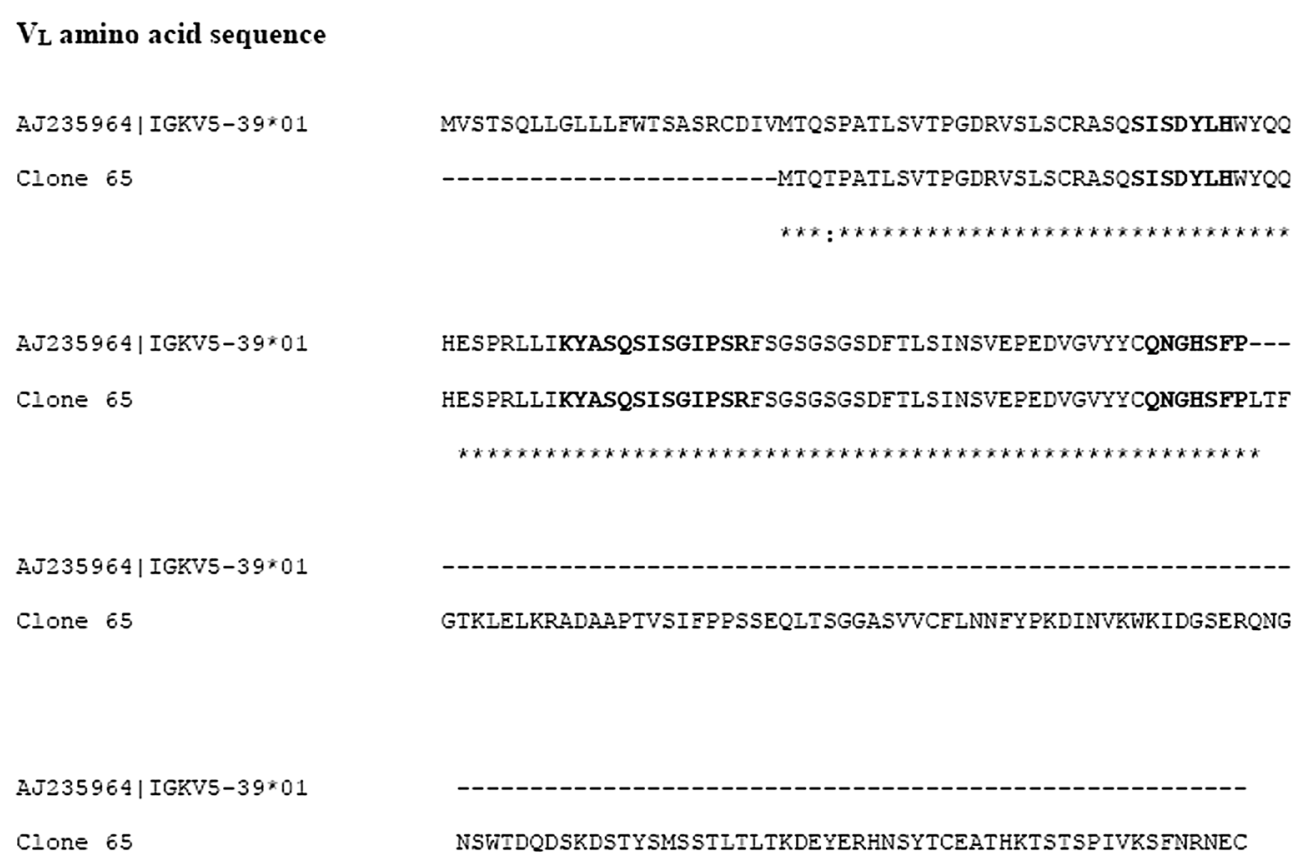

$V_{H}$ amino acid sequence

AC079273|IGHV4-1*01

MDFGL IFFIVAIIKGVQCEVKLIQSGGGIVQPGGSLKLSCAASGIDFSRYWMSWVRRAPG

Clone 65

--------------MAEVQLIESGGGLVQPGGSLKLSCAASGIDFSRYWMSWVRRAPG

AC079273|IGHV4-1*01

KGLEWIGEINPDSSTINYAPSLKDKFIISRDNAKNTLYLQMSKVRSEDTALYYCAR----

Clone 65

KGLEWIGEINPDSSTINYAPSLKDKFIISRDNAKNTLYLQMSKVRSEDTALYYCARRGGG

2C079273| IG:HV4-1*01

Clone 65

YYPYWYFDVWGTGTTVTVSSAKTTAPSVYPLAPVCGGTTGSSVTLGCLVKGYFPEPVTLT

2AC079273| IG:HV4-1*01

Clone 65

WNSGSLSSGVHTFPALIQSGLYTLSSSVIVISNTWPSQIIICNVAHPASSTKVDKKIEPR

AC079273। IGHV4-1*01

Fig. 2 Amino acid sequences of the variable heavy and the light chains from Fab clone 65 compared to the closest germline (IGHV4-01*01 and IGKV5-39*01) sequences as calculated by the IgBLAST software. CDR's are indicated in bold. *indicates identity to the uppermost sequence, - no amino acid at this position, : indicates the existence of different amino acids at this position 


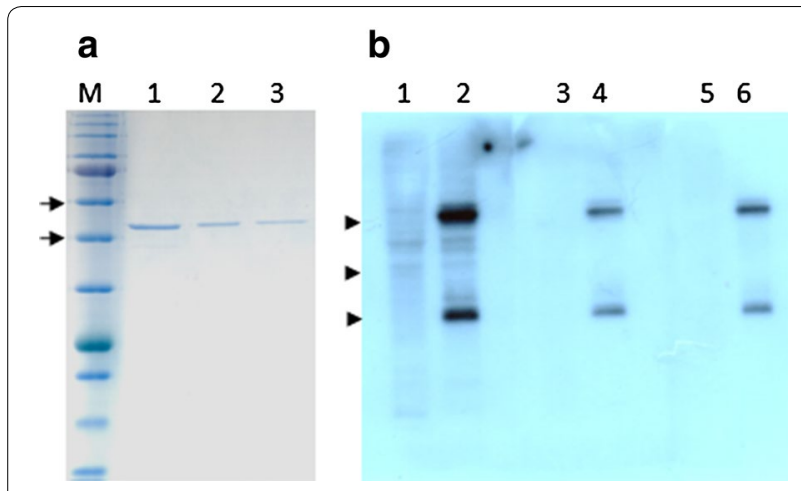

Fig. 3 Purification and reactivity of recombinant Fab fragment from clone 65. a Purification of Fab 65 from E. coli Top 10F' crude extracts after IMAC purification and subsequent affinity purification with protein $L$ agarose beads. Samples were separated under non-reducing conditions in a 10\% polyacrylamide gel stained with coomassie brilliand blue. M: prestained protein standards (NEB, P7712). Lanes 1-3: three eluates of the last purification step from the protein $\mathrm{L}$ agarose beads. Arrows indicate the 46 and $58 \mathrm{kDa}$ molecular mass standard positions, respectively. $\mathbf{b}$ Western blot. Lanes 1-2: probed with a Fab 65 E. coli Top 10F' crude extract, lanes 3-4: probed with a E. coli Top 10F' Fab TT crude extract (kindly provided by the Carlos F. Barbas III laboratory, the Scripps Research Institute), lanes 5-6: probed only with the secondary antibody. Lanes 1, 3, 4: contain $20 \mu \mathrm{g}$ NPCs lysate, lanes 2, 4, 6: contain $20 \mu \mathrm{g}$ mouse spinal cord lysate. Arrowheads indicate the 25, 32 and 46 kDa molecular mass standard positions, respectively

\section{Immunoprecipitation-mass spectrometry}

Fab 65 immunoreactivity in total mouse brain lysate was further estimated in immunoprecipitation experiments (Fig. 6). In this case, mouse brain lysates were incubated with Fab 65, immobilized on protein L agarose beads or control beads. Immunoprecipitated proteins were resolved by SDS-PAGE and silver-stained. Figure 6 shows that a variety of brain proteins were detected by silver stain after incubation of brain lysate with protein L agarose immobilized Fab 65 (lane 1). These proteins are absent in the control reactions run in parallel, which consisted of protein $\mathrm{L}$ agarose beads incubated with the lysate in the absence of the Fab fragment (lane 2) or of the Fab fragment bound protein $\mathrm{L}$ agarose beads in the absence of the protein lysate (lane 3). Since SDS-PAGE was performed under reducing conditions, the two distinct protein bands slightly above the $25 \mathrm{kDa}$ marker in lanes 1 and 3 correspond to the light (expected molecular mass: $25 \mathrm{kDa}$ ) and heavy (expected molecular mass: $32 \mathrm{kDa}$ ) chain of the Fab fragment. In addition, the protein band detected in all three lanes corresponds to protein $\mathrm{L}(36 \mathrm{kDa})$, which was released of the agarose beads after heating. Results from the immunoprecipitation experiments with Fab 65 indicate that the Fab fragment recognizes multiple antigens rather than one in a total mouse brain lysate.
To identify the proteins recognized by Fab 65, we carried out analysis of the protein bands indicated in Fig. 6 by mass spectrometry. This analysis revealed a vast variety of proteins, which precipitated in the presence of Fab 65 (Additional file 2). We assume that, some of these are pooled down non-specifically, since they are probably detected due to their binding to other proteins having affinity to Fab 65.

\section{Discussion}

In the present study we applied the antibody fragment phage display technique for the isolation of reactive monoclonal Fab fragments not to a distinct protein but to potential antigenic proteins existing in the whole NPCs proteome. To achieve that, the Fab phage library was created upon immunization of mice with a syngeneic C57/BL6 lysate, derived from a high number $\left(2 \times 10^{6}\right.$ cells) of NPCs, along with immunization adjuvants. This approach certainly does not simulate the administration of NPCs as transplants for therapeutic purposes, since the presence of CFA in the initial immunization and of IFA in the ensuing boosters, as well as the boosters themselves enhance the humoral response. However, this approach aims at and eventually succeeds in the isolation of monoclonal antibodies with affinity to certain NPCs or brain-derived proteins, thus allowing to investigate the generation of such antibodies after a "regular" NPC transplantation into the mouse CNS as well as the effects these may have.

A common problem associated with transplantations is the low survival rate of neural progenitors after engraftment [10]. Antigens from cells that do not survive may trigger immune responses, hence the CNS is no more considered as an immunologically privileged site. In fact, there are indications that repeated CNS allografts may evoke immunization reactions [11]. Moreover, it has been shown that humoral response from immunized animals with myelin oligodendrocyte glycoprotein$\mathrm{MOG}_{35-55}$ produces antibodies that may target and affect NPCs of the SVZ niche, cells that are the orchestrators of neuronal remyelination [12].

The immunized phage library that was created consists of $2.5 \times 10^{6} \mathrm{cfu}$ and is considered to be moderate, since more but even less complex libraries have been reported. As a measure, an immunized phage display library contains $99 \%$ of all antibody molecules when $1 \times 10^{7}$ individual clones are represented $[13,14]$. Since the phagemids of the created library are stored, a freshly prepared library could be easily reamplified on demand. This would enable us to further screen for the existence of IgG Fab fragments recognizing distinct NPCs antigens should this be considered relevant in the future. 

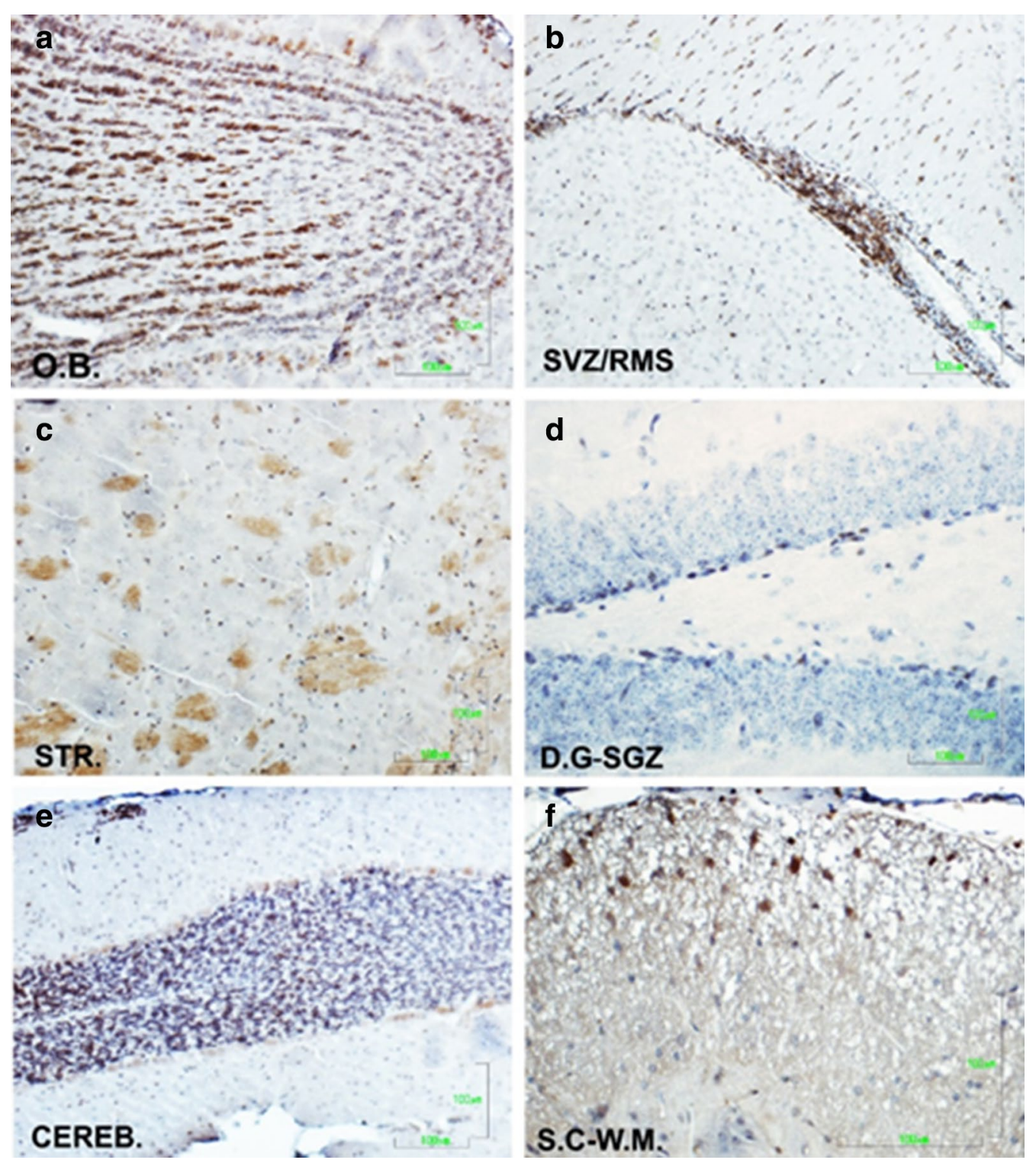

Fig. 4 Immunohistochemistry of different mouse brain and spinal cord regions using Fab 65 crude extract as primary antibody. Cells expressing antigens recognized by Fab 65 are stained brown. a O.B.: olfactory bulb, b SVZ/RMS: subventricular zone/rostral migratory stream of the SVZ, c STR.: striatum, d D.G-SGZ: subgranular zone of the dentate gyrus, e CEREB.: cerebellum, f S.C-W.M.: white matter of the spinal cord. Scale bars $=100 \mu \mathrm{m}$

Expression of recombinant Fab fragments in the periplasm of E. coli cells using shake flasks often leads to relatively low yields, depending on several factors [15]. In fact, most Fab clones isolated in the current study displayed poor yields. However, clone 65 was expressed in satisfactory amounts, with a yield of about $1.0 \mathrm{mg} \mathrm{l}^{-1}$ of culture. Expressed Fab was used in immunoblotting and IHC experiments preferably as crude extract as previously described [16] in order to minimize activity reduction occurring during handling for purification purposes. In these experiments, Fab 65 performed better than the other clones, in terms of recognizing NPCs or CNS antigens.

In immunoblotting and immunoprecipitation experiments, Fab 65 was shown to recognize not only one specific but rather multiple proteins, a characteristic of low affinity polyreactive antibodies [17]. This is supported also by the $100 \%$ homology observed in its primary structure, compared to the closest germline antibody (Fig. 2). Such antibodies might have an advantage in the biopanning procedure, since the Fab phage library interacts with the multiple proteins present in the NPCs lysate. 


\section{a}
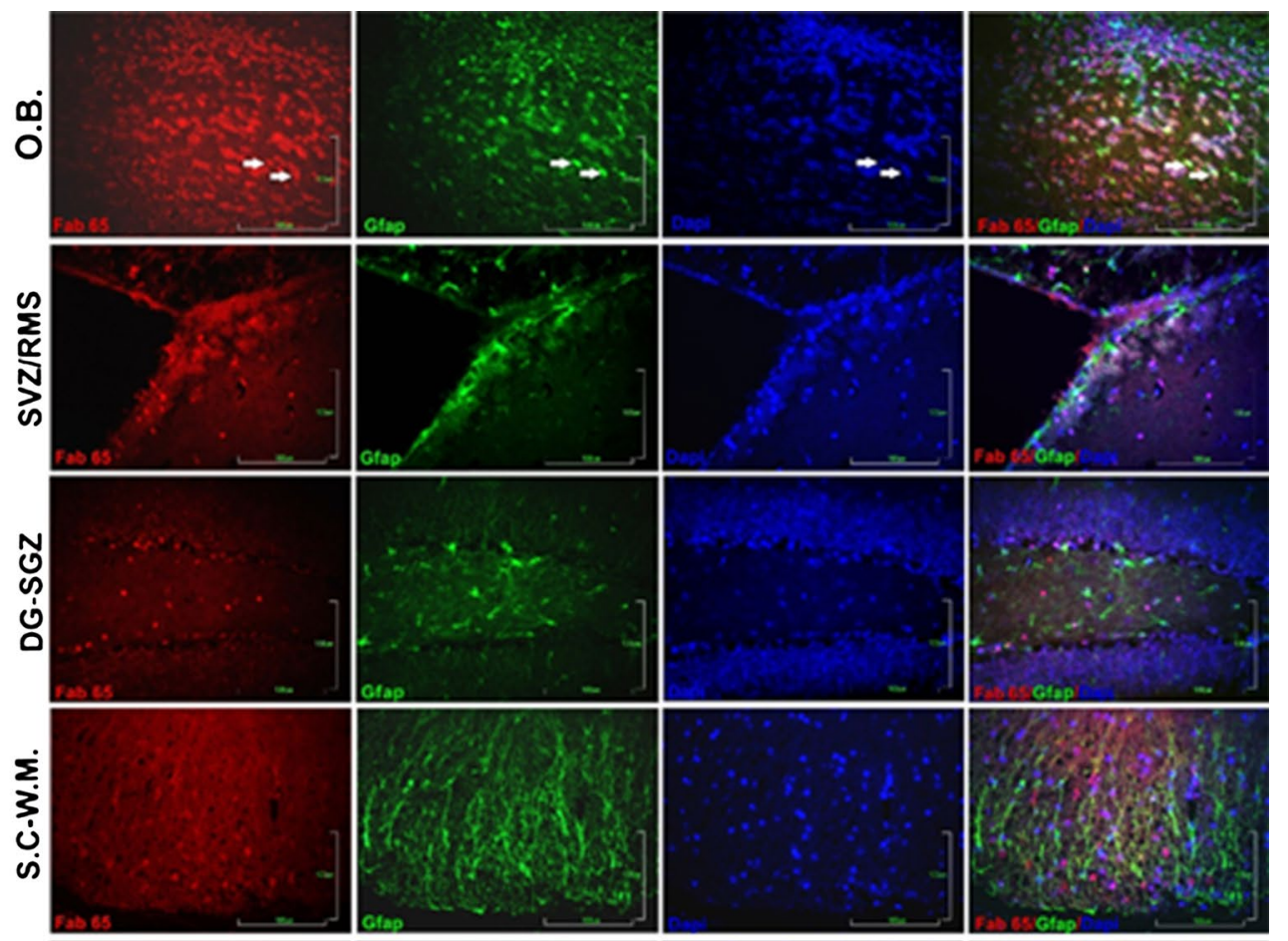

b
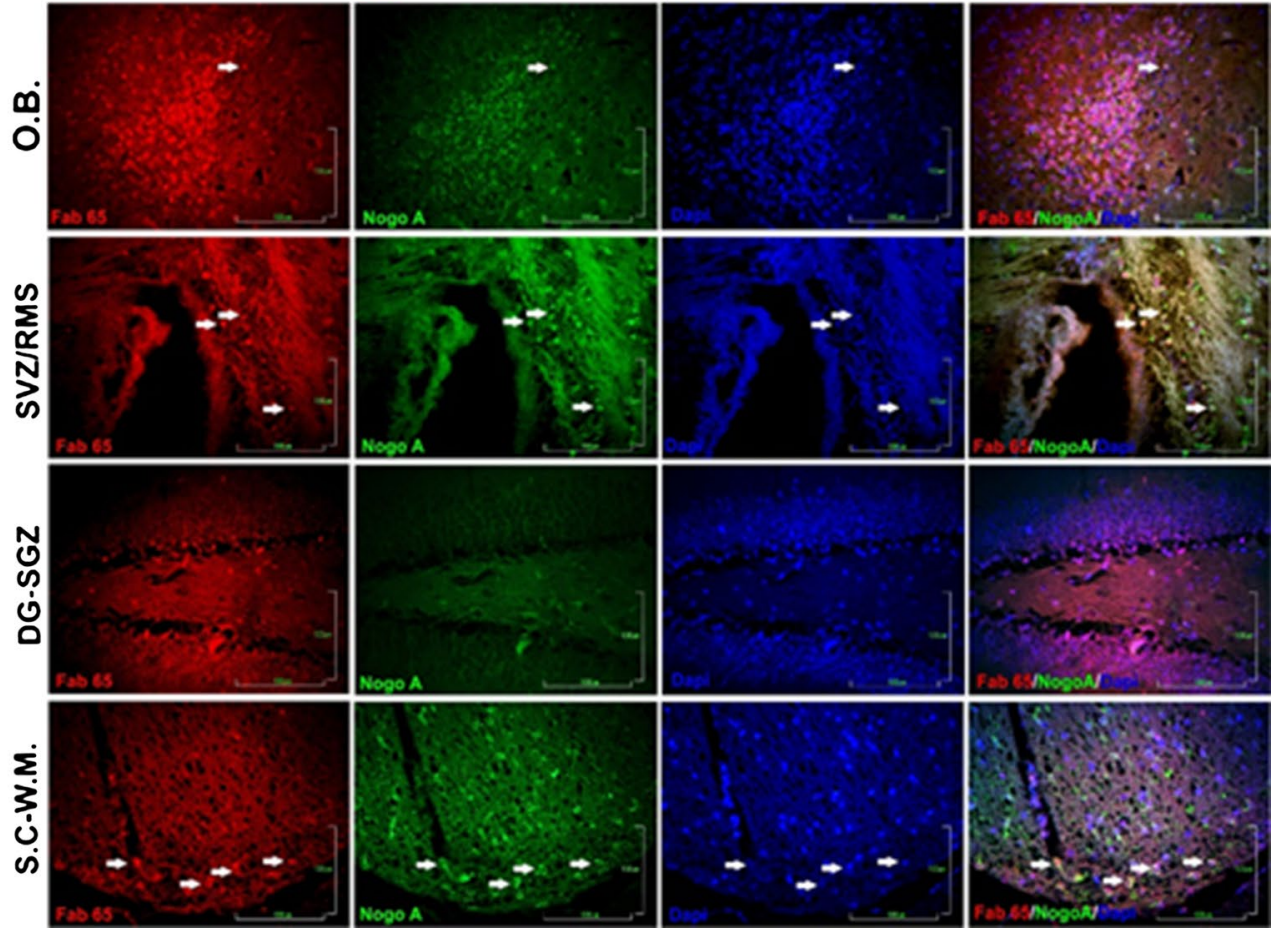

Fig. 5 Double immunofluorescence of different mouse CNS regions probed with recombinant Fab65 and a commercial a GFAP or b Nogo A antibody. O.B.: olfactory bulb, SVZ/RMS: rostral migratory stream of the SVZ, DG-SGZ: subgranular zone of the dentate gyrus, and S.C-W.M.: white matter of the spinal cord. Sections probed with Fab 65 (red) and anti-GFAP or anti-NOGO A (green). Arrows indicate representative cells with observed co-expression of the Fab 65 recognised antigen(s) with GFAP. Cell nuclei were stained with DAPI. Scale bars $=100 \mu \mathrm{m}$ 


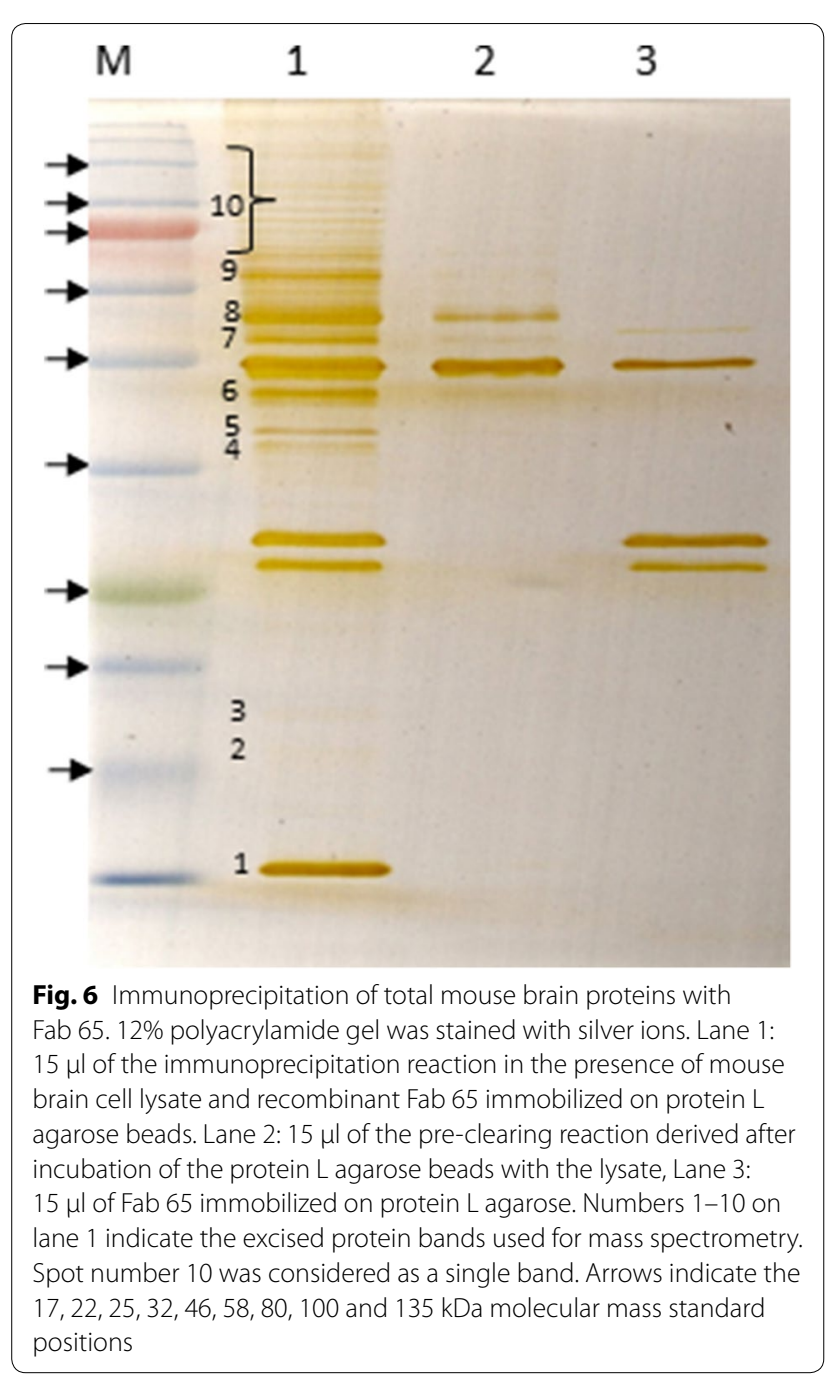

IHC experiments showed that Fab 65 is able to bind to cell antigens in the different mouse brain regions tested. Other Fab clones isolated were able to react with cell antigens in some of the brain regions tested, while others showed no reactivity at all. For example, Fab from clone 17 reacted with antigens on neuronal axons, cells in the subventricular zone and the white matter of the spinal cord but no signal was detected on parenchymal cells of the brain. Furhter, Fab's from clones 68 and 49 showed no reactivity in none of the tested brain regions. As shown in Additional file 1, dIF experiments revealed that Fab 65 binds mainly to antigens on cells expressing Nogo A, a specific oligodendrocyte marker, and the highest co-localization signal, $\sim 50 \%$, was observed in the white matter of the spinal cord.

Immunoprecipitation and mass spectrometry analyses did not indicate any clear Fab 65 binding candidate(s). Interestingly, the highest scoring protein in the intense band 1 immunoprecipitated by Fab 65 (Fig. 6) was identified by mass spectrometry to be $\beta$-globin. It remains unclear whether this finding should be attributed to the $\beta$-globin, present in dopaminergic neurons, astrocytes and oligodendrocytes [18] or to tissue blood contamination.

Due to the high number of proteins identified by Fab 65 , binding specificity is difficult to estimate. However, we are in the process of transforming the Fab fragment into full IgG antibody and express it in eukaryotic cell lines. We anticipate that the full IgG glycosylated antibody will be generated with much improved yields and most importantly it will have enhanced affinity and avidity, due to the bivalency and the presence of the Fc region [19].

\section{Conclusions}

By creating an immunized Fab fragment phage display library, we were able to isolate more than 20 monoclonal Fab's reacting with NPCs antigens. One clone, clone 65, was expressed as recombinant Fab in E. coli cells in adequate amounts. More importantly, this clone was reactive against NPCs or other mouse brain cell antigens in different immunological tests. Our data show that Fab 65 does recognize multiple antigens rather than one specific protein. The reactivity of the other clones requires more detailed investigation. Whether such antibodies might be generated during NPCs transplantations for therapeutic purposes and the effects these antibodies may have will be investigated in future experiments.

\section{Methods}

\section{Neurospheres preparation}

Neurospheres were prepared from NPCs derived from brain hemispheres of newborn C57BL/6 mice as previously described [12]. Briefly, isolated NPCs from the brain hemispheres were initially treated with trypsin, then mechanically dissociated and afterwards resuspended in DMEM/F2 media containing the N-2 supplement (Invitrogen, Carlsbad, USA). Cells were cultured for 7 days at $37{ }^{\circ} \mathrm{C}, 10 \% \mathrm{CO}_{2}$ in the presence of $10 \mu \mathrm{g} \mathrm{ml}^{-1}$ basic fibroblast growth factor (bFGF) and $10 \mu \mathrm{g} \mathrm{ml}^{-1}$ epidermal growth factor (EGF). Developed neurospheres were harvested by centrifugation. About $10^{6}$ cells were resuspended for protein extraction in $100 \mu \mathrm{l}$ lysis buffer containing $25 \mathrm{mM}$ Tris $\mathrm{pH} 7.5,150 \mathrm{mM} \mathrm{NaCl}, 1 \mathrm{mM}$ DTT, $1 \mathrm{mM}$ PMSF, $1 \%$ Triton X-100, $12 \mu \mathrm{g} \mathrm{ml}^{-1}$ leupeptin and $5 \mu \mathrm{g} \mathrm{ml}^{-1}$ aprotinin. Incubation for $15 \mathrm{~min}$ was followed by centrifugation for $10 \mathrm{~min}$ at $10,000 \times g$ at room temperature to remove cell debris. The resulting supernatant was aliquoted and stored at $-80{ }^{\circ} \mathrm{C}$ for future use. Protein content was estimated by the Bradford method. 


\section{Immunization}

Two 6-week-old C57BL/6 male mice were immunized subcutaneously with $200 \mu \mathrm{l}$ of protein lysate derived from $2 \times 10^{6}$ NPCs in sterile phosphate buffered saline (PBS) $\mathrm{pH}$ 7.4. Cells were stored frozen at $-80{ }^{\circ} \mathrm{C}$. Before immunization cells were emulsified in complete Freund's adjuvant (CFA) in a ratio of 1:1. Booster immunizations with the same dosage were performed similarly 2,4 and 8 weeks after the initial immunization, using incomplete Freund's adjuvant (IFA). Spleens were harvested and processed for RNA extraction. Blood was collected via submandibular bleeding before and after immunization to obtain preimmune and immune sera.

\section{RNA extraction and amplification of Fab fragment sequences}

Total RNA was extracted using the Trizol reagent (Invitrogen, Carlsbad, USA) following the manufacturer's instructions. Tissue was homogenized using the Ribolyzer apparatus with $1 \mu \mathrm{m}$ ceramic beads for three cycles of $20 \mathrm{~s}$ each (at setting 4). In a second purification step, mRNA was extracted from the total RNA generated in the previous step, using the poly A Spin mRNA isolation kit (NEB, Ipswich, USA) following the manufacturer's instructions. Isolated mRNA was quantified with the NanoDrop apparatus (Thermo Fisher Scientific, Waltham, USA).

$10 \mu \mathrm{g}$ of mRNA were subjected to cDNA synthesis with the iScript cDNA synthesis kit (Biorad, Hercules, USA). cDNAs were pooled and used as template for PCR amplification of the IgG Fab fragments i.e. the heavy chain variable domains $\left(\mathrm{V}_{\mathrm{H}}\right)$ and the constant framework region $1\left(\mathrm{C}_{\mathrm{H} 1}\right)$ along with the $\mathrm{k}$ light chains (variable $V_{K}$ and constant $C_{K}$ domains), with the PCR primers given in Additional file 3. PCR was performed with Q5 high fidelity DNA polymerase (NEB, Ipswich, USA). For heavy chain $(\mathrm{HC})$ fragment amplification primer pairs of each primer 1-7 as forward and each primer 8-11 as reverse were used. Similarly, primer combinations for light chain amplification included primer 19 as reverse primer and one of the primers $12-18$ as forward. After an initial denaturation step at $94{ }^{\circ} \mathrm{C}$ for $5 \mathrm{~min}, \mathrm{HC}$ fragment cyclic amplification conditions were: $94{ }^{\circ} \mathrm{C}$ for $20 \mathrm{~s}, 68^{\circ} \mathrm{C}$ for $20 \mathrm{~s}, 72{ }^{\circ} \mathrm{C}$ for $1 \mathrm{~min}$ (35 cycles) and finally $72{ }^{\circ} \mathrm{C}$ for $7 \mathrm{~min}$. The same conditions were applied for LCs amplification, except for the annealing temperature, which was set at $56{ }^{\circ} \mathrm{C}$. The products from all HC PCRs were pooled together, as were the products from the LC PCRs and then resolved in a $1.8 \%$ TAE agarose gel. The $\sim 680$ bp products were gel-excised and purified with the Nucleospin Gel and PCR Clean Up kit (Macherey-Nagel, Düren, Germany) according to the manufacturer's instructions. Purified products were stored at $-20{ }^{\circ} \mathrm{C}$ until needed.

\section{Cloning into pComb3XSS vector}

pComb3XSS vector was kindly provided by the Carlos F. Barbas III laboratory (Scripps Research Institute). Cloning of the Fab fragment sequences was performed as described previously [20]. In more detail, $2 \mu \mathrm{g}$ of the vector and approximately $400 \mathrm{ng}$ of PCR amplified LCs were mixed in separate reactions with restriction enzymes $\mathrm{SacI}$ (TaKaRa, Kyoto, Japan) $20 \mathrm{U}$ and XbaI (TaKaRa, Kyoto, Japan) $30 \mathrm{U}$ in $1 \times$ buffer $M$ and incubated overnight at $37^{\circ} \mathrm{C}$, followed by heat inactivation for $10 \mathrm{~min}$ at $65{ }^{\circ} \mathrm{C}$. Reaction products were separated in a $1.2 \%$ TAE agarose gel and both the restriction-digested vector and the DNA coding for the LCs were gel-excised and purified as above. Purified products were quantified in Nanodrop apparatus and $\mathrm{LC}$ sequences were ligated to the corresponding $\mathrm{SacI} / \mathrm{Xba \textrm {I }}$ sites of the vector. Ligation products were purified by sodium acetate precipitation and electroporated into electrocompetent E. coli XL-1 Blue cells, using the MicroPulser apparatus (Biorad, Hercules, USA). A small aliquot of the transformed $E$. coli cells was used for titration of the transformants; the remaining cells were incubated overnight at $37{ }^{\circ} \mathrm{C}$ in $500 \mathrm{ml}$ Super Broth (SB, $30 \mathrm{~g} \mathrm{l}^{-1}$ tryptone, $20 \mathrm{~g} \mathrm{l}^{-1}$ yeast extract, $10 \mathrm{~g} \mathrm{l}^{-1} \mathrm{MOPS}$ $\mathrm{pH}$ 7.0) in the presence of $100 \mu \mathrm{g} \mathrm{ml}^{-1}$ carbenicillin and $15 \mu \mathrm{g} \mathrm{ml}^{-1}$ tetracycline. The vector containing the LCs sequences was purified using the maxi prep kit (Macherey-Nagel, Düren, Germany) and used for the cloning of the $\mathrm{HC}$ fragments. To this end, $1 \mu \mathrm{g}$ of the PCR-amplified $\mathrm{HC}$ fragments and $5 \mu \mathrm{g}$ of the pComb-LC library derived in the previous step, were digested overnight at $37{ }^{\circ} \mathrm{C}$ with $60 \mathrm{U}$ of the enzymes SpeI HF and XhoI (both from NEB, Ipswich, USA) in $1 \times$ cut smart buffer. After a heat inactivation step at $80{ }^{\circ} \mathrm{C}$ for $10 \mathrm{~min}$, digestion products were separated in a $1.2 \%$ agarose gel in TAE, gel-excised and purified as before. Purified products were quantified in Nanodrop apparatus and $\mathrm{HC}$ sequences were ligated to the corresponding SpeI/XhoI sites of the vector. Ligation products were purified by precipitation with sodium acetate and electroporated into electrocompetent $E$. coli $X L-1$ Blue cells. Titration of the derived transformants was performed by plating serial dilutions of a small aliquot on LB plates (10 $\mathrm{g} \mathrm{l}^{-1}$ tryptone, $5 \mathrm{~g} \mathrm{l}^{-1}$ yeast extract, $5 \mathrm{~g} \mathrm{l}^{-1} \mathrm{NaCl}, 17 \mathrm{~g} \mathrm{l}^{-1}$ agar, $\left.\mathrm{pH} 7.0\right)$ containing $50 \mu \mathrm{g} \mathrm{ml}^{-1}$ carbenicillin and $15 \mu \mathrm{g} \mathrm{ml}^{-1}$ tetracycline. Carbenicillin $100 \mu \mathrm{g} \mathrm{ml}^{-1}$ and tetracycline $15 \mu \mathrm{g} \mathrm{ml}^{-1}$ were added to the transformed cells SB and incubated for $2 \mathrm{~h}$ at $37{ }^{\circ} \mathrm{C}$ with vigorous shaking before the addition of $2 \times 10^{11}$ pfu of the helper phage M13KO7 (NEB, Ipswich, USA), which was followed by further overnight incubation under the same conditions. Bacteria cells were pelleted by centrifugation at $3000 \times g$ for $15 \mathrm{~min}$ at $4{ }^{\circ} \mathrm{C}$ and processed for phagemid purification. Phages were purified from the supernatant by $4 \% \mathrm{w} / \mathrm{v}$ PEG $8000,3 \% \mathrm{w} / \mathrm{v} \mathrm{NaCl}$ 
precipitation for $30 \mathrm{~min}$ at $4{ }^{\circ} \mathrm{C}$. The final phage pellet, corresponding to the Fab phage display library, was resuspended in sterile TBS (50 mM Tris $\mathrm{pH} 7.5,150 \mathrm{mM}$ $\mathrm{NaCl}$ ) containing $1 \%$ bovine serum albumin (BSA) and stored at $4{ }^{\circ} \mathrm{C}$.

\section{Biopanning of the Fab library on NPCs protein lysates}

Phage clones from the immune library displaying IgG antibody Fab fragments with affinity to NPCs proteins were selected and enriched by the biopanning procedure [20]. NPCs proteins were immobilized on nitrocellulose membrane, an approach reported to be efficient in similar experiments [21]. $20 \mu \mathrm{g}$ of a NPCs lysate were separated by SDS-PAGE on a $12 \%$ polyacrylamide gel and electrotransferred as described in the immunoblotting section. Nitrocellulose membrane was cut in strips and non-specific binding sites were blocked with PBS containing 2\% BSA. Furthermore, pure nitrocellulose strips with no protein bound were similarly blocked. These served as a substrate on which $50 \mu \mathrm{l}$ (about $10^{11} \mathrm{pfu}$ ) of the Fab phage library diluted in $450 \mu \mathrm{l}$ PBS, $0.1 \% \mathrm{v} / \mathrm{v}$ Tween 20 were incubated for $30 \mathrm{~min}$ at room temperature to remove nitrocellulose and/or BSA binding clones from the supernatant. Last was removed and incubated with the NPCs proteins immobilized on a nitrocellulose strip for $2 \mathrm{~h}$ at room temperature. The strip was washed $5 \times$ with $5 \mathrm{ml}$ PBST. Bound phage clones were eluted by incubation of the strip for $10 \mathrm{~min}$ at room temperature with a low $\mathrm{pH}$ buffer (100 mM glycine $\mathrm{pH} 2.2)$. The eluate was neutralized with $2 \mathrm{M}$ Tris base. Serial dilutions of an aliquot were used for the titration of the phages in the eluate by infecting an E. coli XL-1 Blue culture and plating on LB plates containing $50 \mu \mathrm{g} \mathrm{ml}^{-1}$ carbenicillin and $15 \mu \mathrm{g} \mathrm{ml}^{-1}$ tetracycline. An E. coli XL-1 Blue culture in $\mathrm{SB}$ media at $\mathrm{OD}_{600}=0.8-1.0$ was infected with the eluate in the presence of the above antibiotics and super infected with the M13 helper phage as previously described [20]. Propagated phage was purified, titered as before and served as the input phage for the second round of biopanning. In total, three biopanning rounds were performed. To enhance stringency of the selection conditions, PBS $0.5 \% \mathrm{v} / \mathrm{v}$ Tween 20 was used by washing in round two and three. Also, washing step number was increased to 10 and 15 in round two and three, respectively. After completion of round three, phage infected $E$. coli XL-1 Blue clones on LB plates containing $50 \mu \mathrm{g} \mathrm{ml}^{-1}$ carbenicillin and $15 \mu \mathrm{g} \mathrm{ml}^{-1}$ tetracycline were picked for phagemid isolation with the Nucleospin plasmid kit (Macherey-Nagel, Düren, Germany). Chemically competent E. coli Top10F' cells were transformed with aliquots of the phagemid. Transformants were plated on LB plates containing $50 \mu \mathrm{g} \mathrm{ml} \mathrm{g}^{-1}$ carbenicillin and incubated overnight at $37{ }^{\circ} \mathrm{C}$. Single colonies were picked up and cultured in $\mathrm{SB}, 100 \mu \mathrm{g} \mathrm{ml}^{-1}$ carbenicillin for plasmid isolation, which was further used for DNA sequencing or for the expression of recombinant Fab fragments.

\section{Sequence analysis}

DNA sequencing of the plasmids was performed at CeMIA SA (Greece) by the Sanger method using primers 20-21 (Additional file 3) as forward and reverse primer, respectively. Nucleic acid sequences were analyzed with the IMGT/V-QUEST software [22] while the corresponding amino acid variable domains were analyzed with IgBLAST [23] in order to identify the germlines and to locate the complementarity determining regions (CDRs) of the IgG Fab fragments expressing clones.

\section{Expression of recombinant Fab fragments}

Monoclonal recombinant IgG Fab fragments were expressed in E. coli Top 10F cells. A liquid culture in $\mathrm{SB}, 100 \mu \mathrm{g} \mathrm{ml}^{-1}$ carbenicillin, 1\% w/v glucose (sterile filtrated) was set up by picking a colony from freshly transformed cells. After overnight incubation at $37^{\circ} \mathrm{C}$ with shaking, the culture was diluted 1:100 in $500 \mu \mathrm{l} \mathrm{SB}$, $100 \mu \mathrm{g} \mathrm{ml}^{-1}$ carbenicillin, $0.1 \% \mathrm{w} / \mathrm{v}$ glucose and incubated as before until $\mathrm{OD}_{600}=0.8$ was reached. At that point, $\mathrm{MgCl}_{2}$ (20 mM final concentration) was added, while $\mathrm{Fab}$ expression was induced by the addition of $0.5 \mathrm{mM}$ isopropyl-D-thiogalactopyranoside (IPTG). Culture was incubated for $24 \mathrm{~h}$ at $25^{\circ} \mathrm{C}$ with shaking. Bacteria cells were pelleted by centrifugation at $3000 \times g$, $4{ }^{\circ} \mathrm{C}$ for $30 \mathrm{~min}$. Cells were resuspended in $20 \mathrm{ml}$ PBS and treated with $20 \mathrm{mg} \mathrm{ml}^{-1}$ lysozyme for $30 \mathrm{~min}$ at room temperature. Further, cell suspension underwent three freeze-thaw cycles. Released bacterial DNA was digested by DNase I $\left(0.5 \mathrm{mg} \mathrm{ml}^{-1}\right.$ for $15 \mathrm{~min}$ at room temperature). Cell-debris was removed by centrifugation $\left(10,000 \times g\right.$ for $15 \mathrm{~min}$ at $\left.4{ }^{\circ} \mathrm{C}\right)$. The supernatant, containing Fab fragments, was aliquoted and stored at $-20{ }^{\circ} \mathrm{C}$. This crude extract was either used directly for antigen detection by immunoblot/IHC or for Fab fragment purification. Soluble Fabs were first purified over the His-tag of the Fab heavy chain by Ni-chelate affinity chromatography with Protino Ni-NTA agarose (Macherey-Nagel, Düren, Germany) following the manufacturer's instructions. Eluates were diluted 1:1 with PBS and mixed with protein $\mathrm{L}$ agarose beads (ABT). After incubation for $1 \mathrm{~h}$ under rotation at room temperature, samples were centrifuged at $100 \times g, 5 \mathrm{~min}$ at room temperature. Pellet was washed $2 \times$ with $1 \mathrm{ml}$ PBS and the purified Fab finally eluted with $0.1 \mathrm{M}$ citric acid $\mathrm{pH} 2.8 \mathrm{pH}$ of the eluates was neutralized immediately with $1 \mathrm{M}$ Tris $\mathrm{pH}$ 9.0. 
SDS-PAGE electrophoresis and immunoblotting

SDS-PAGE electrophoresis was conducted according to the Leammli method [24] on 10 or $12 \%$ polyacrylamide gels. For immuno-detection, separated proteins were transferred onto PVDF membranes, blocked with blocking buffer (PBS, 0.1\% v/v Tween 20,5\% w/v non fat dried milk) for $1 \mathrm{~h}$ at room temperature. Blots were incubated with Fab preparations diluted 1:1 in blocking buffer as specified for additional $2 \mathrm{~h}$. After $4 \times$ wash steps in PBS $0.1 \%$ Tween 20 for 10 min, membranes were incubated with a HRP-conjugated anti mouse antibody diluted in blocking buffer and washed as before. Reactivity was visualized with the ECL reagent. Where necessary, separated proteins were stained non-specifically with coomassie brilliant blue or for enhanced sensitivity with silver ions.

\section{Immunohistochemistry-immunofluorescence}

Immunohistochemistry and immunofluorescence experiments were performed on naive mouse C57BL/6 paraffin brain sections as described in [12]. As primary antibodies, E. coli Top 10F' crude extract preparations were used, diluted 1:5 in PBS containing 10\% FBS. The reactivity assessment of the different Fab clones was visualized by developing with DAB under an optical microscope. dIF experiments were performed for the co-expression estimation of Fab 65 reactive antigens with Nogo A and/ or GFAP proteins, which served as oligodendrocytes and astrocytes markers, respectively. Both marker molecules were detected with commercial anti-rabbit antibodies (Santa Cruz Biotechnology, Santa Cruz, USA). 4',6-diamidino-2-phenylindole (DAPI) staining was followed in order to visualize cell nuclei. Fluorescence microscope images were analyzed using the ImageJ 1.52 b software [25].

\section{Immunoprecipitation}

The Fab fragment from clone 65 was first purified by Nichelate affinity chromatography using $0.5 \mathrm{ml}$ of a Fab 65 E. coli Top10F crude extract preparation. The $250 \mathrm{mM}$ imidazole-containing eluate was diluted 1:1 with PBS and incubated with $50 \mu \mathrm{l}$ of protein $\mathrm{L}$ agarose beads in order to remove impurities copurified on the Ni-NTA column. Affinity purification was performed as described above. After the last centrifugation step, instead of eluting, beads were incubated with $1 \mathrm{ml}$ of a precleared mouse brain homogenate in RIPA buffer $(150 \mathrm{mM} \mathrm{NaCl}, 1.0 \% \mathrm{v} / \mathrm{v}$ IGEPAL CA-630, $0.5 \% \mathrm{w} / \mathrm{v}$ sodium deoxycholate, $0.1 \%$ $\mathrm{w} / \mathrm{v}$ SDS, $50 \mathrm{mM}$ Tris, $\mathrm{pH}$ 8.0) containing about $3 \mathrm{mg}$ of total protein. Incubation was performed for $3 \mathrm{~h}$ at room temperature on a test tube rotator. The mix was centrifuged at $100 \times g, 5 \mathrm{~min}$ at room temperature. The pellet containing the Fab 65 bound protein $\mathrm{L}$ agarose beads and possible pulled down proteins was washed $3 \times$ with $1 \mathrm{ml}$ PBS. After the last centrifugation step, the supernatant was aspirated and $60 \mu \mathrm{l}$ of $2 \times$ sample buffer were added. For preclearing, mouse brain homogenate was incubated with $50 \mu \mathrm{l}$ of protein $\mathrm{L}$ agarose beads for $1 \mathrm{~h}$ as described above. Protein L agarose beads were handled as the immunoprecipitation sample, as an assessment for mouse brain proteins with affinity to the agarose beads. A negative control reaction consisted of Fab 65 bound protein $\mathrm{L}$ agarose in the absence of any brain protein lysate. In all cases, proteins were heated at $95^{\circ} \mathrm{C}$ for $5 \mathrm{~min}$, separated into a $12 \%$ polyacryamide gel and stained subsequently with silver ions as described [26].

\section{In-gel digestion of proteins with trypsin}

In gel protein digestion was performed according to standard procedures [27]. Briefly, the gel pieces were destained, and subjected to two cycles of dehydration with acetonitrile $(\mathrm{ACN})$ and rehydration with $25 \mathrm{mM}$ $\mathrm{NH}_{4} \mathrm{HCO}_{3}$ buffer. Followed dehydration with $\mathrm{ACN}$, the dried gel pieces were rehydrated with $12.5 \mathrm{ng} \mathrm{Hl}^{-1}$ trypsin (Trypsingold, Promega, Madison, USA) in $25 \mathrm{mM}$ $\mathrm{NH}_{4} \mathrm{HCO}_{3}$ buffer and incubated over night at $37^{\circ} \mathrm{C}$. Peptides were extracted from the gel with $100 \mu$ l extraction buffer $\left[1: 2(\mathrm{v} / \mathrm{v}) 5 \%\right.$ formic acid/ACN] for $30 \mathrm{~min}$ at $37^{\circ} \mathrm{C}$ and the solution was transferred and dried in a vacuum centrifuge. Finally, the samples were reconstituted in $2 \%$ $\mathrm{v} / \mathrm{v}$ ACN $/ 0.1 \% \mathrm{v} / \mathrm{v}$ formic acid and sonicated in a water bath for $5 \mathrm{~min}$.

\section{LC-MS/MS analysis}

The purified peptides were analyzed by HPLC-tandem MS/MS using a C-18 column coupled to a LTQ Orbitrap XL Mass spectrometer (Thermo Scientific, Waltham, USA). $10 \mu \mathrm{l}$ of peptides were pre-concentrated at a flow of $5 \mu \mathrm{l} \mathrm{min}{ }^{-1}$ for 10 min using a C18 trap column (Acclaim PepMap RSLC, Thermo Scientific, Waltham, USA) and then loaded onto a $15 \mathrm{~cm} \mathrm{C18} \mathrm{column}(75 \mu \mathrm{m}$ ID, particle size $2 \mu \mathrm{m}, 100 \AA$, Acclaim PepMap RSLC, Thermo Scientific, Waltham, USA). The binary pumps of the HPLC (RSLC nano, Thermo Scientific, Waltham, USA) contained solution A [2\% (v/v) ACN in $0.1 \%(\mathrm{v} / \mathrm{v})$ formic acid] and solution B (80\% ACN in $0.1 \%$ formic acid). The peptides were separated using a linear gradient of $4-40 \% \mathrm{~B}$ in $60 \mathrm{~min}$ at a flow rate of $300 \mathrm{nl} \mathrm{min}{ }^{-1}$. The column was placed in an oven operating at $35{ }^{\circ} \mathrm{C}$. Full scan MS spectra were acquired in the orbitrap $(\mathrm{m} / \mathrm{z} 300$ 1600) in profile mode and data-dependent acquisition with the resolution set to 60,000 at $\mathrm{m} / \mathrm{z} 400$ and automatic gain control target at 106 . The six most intense ions were sequentially isolated for collision-induced MS/MS 
fragmentation (normalized CID of 35\%) and detection in the linear ion trap. Dynamic exclusion was set to $60 \mathrm{~s}$. Ions with single charge states were excluded. Lockmass of $\mathrm{m} / \mathrm{z} 445,120,025$ was used for internal calibration. The software Xcalibur (Thermo Scientific, Waltham, USA) was used to control the system and acquire the raw files.

\section{Data analysis and database search}

Peptides were identified using the Proteome Discoverer 1.4 software tools (Thermo Scientific, Waltham, USA). The Orbitrap raw data (peak $\mathrm{S} / \mathrm{N}$ threshold was set to 1.5) were searched using SEQUEST HT against the uniprot mouse FASTA database with strict trypsin specificity and with maximum two missed cleavages and variable modifications of methionine oxidation and acetylation of the $\mathrm{N}$-terminus. The peptides were filtered based on their Xcorr values versus peptide charge states (XCorr $>2.0$ for charge state +2 and XCorr $>2.5$ for charge state +3$)$.

\section{Supplementary information}

Supplementary information accompanies this paper at https://doi. org/10.1186/s40709-020-00123-4.

Additional file 1. Plot illustrating double immunofluorescence experiment results concerning co-expression of the Fab 65 recognised antigen(s) with GFAP or NOGO. A. Co-expression with GFAP is observed only in the olfactory bulb (O.B) at about 17\%. Co-expression with NOGO A is observed in the olfactory bulb, in the subventricular zone/rostral migratory stream of the SVZ (SVZ/RMS) and in white matter of the spinal cord (SCMM) at about 33\%, 51 and 58\% respectively. No co-expression with neither of the glial marker antigens was detected in the subgranular zone of the dentate gyrus (DG/SGZ). Statistical analysis was performed with the GraphPad Prism 5.0 software using the Shapiro-Wilk and Kolmogorov-Smirnov tests. Values were analyzed by the ANOVA test followed by the Bonferoni post hoc test. Graph shows mean values and the standard error of the mean out of three different regions of the sections tested. Bars indicate the standard error of the mean of three different section regions analyzed.

Additional file 2. Mass spectrometric analysis results of Fab 65 immunoprecipitated brain protein bands. Immunoprecipitated proteins from a whole C57/BL6 mouse brain lysate using recombinant Fab 65 were electrophoretically separated onto a $12 \%$ polyacrylamide gel. Protein bands were excised as they are numbered on Fig. 6 and analyzed by mass spectrometry. As "Protein Band 10" is referred the whole region indicated on the figure. The proteins listed presended the highest counts regarding the parameter of unique peptides. Numbering is the same as on Fig. 6.

Additional file 3. PCR primers used in this study. Primers 1-19 were used for the amplification of IgG Fab fragments, while primers 20-21 for the sequencing of the isolated phagemids.Degenerative nucleotide symbols: $\mathrm{K}=\mathrm{G}$ or $\mathrm{T}, \mathrm{S}=\mathrm{C}$ or $\mathrm{G}, \mathrm{M}=\mathrm{A}$ or $\mathrm{C}, \mathrm{W}=\mathrm{A}$ or $\mathrm{T}, \mathrm{R}=\mathrm{A}$ or $\mathrm{G}, \mathrm{Y}=\mathrm{C}$ or T. Restriction enzymes recognition sites are underlined, with A|CTAGT for Spel, C|TCGAG for Xhol, T|CTAGA for Xbal and GAGCT|C for Sacl.

\section{Abbreviations}

bFGF: Basic fibroblast growth factor; CFA: Complete Freund's adjuvant; cfu: Colony forming units; CNS: Central nervous system; DAB: 3,3' Diaminobenzidine-tetra-hydrochloride; DAPI: 4',6-Diamidino-2-phenylindole; ECL: Enhanced chemiluminescence; EGF: Epidermal growth factor; GFAP: Glial fibrillary acidic protein; HRP: Horse radish peroxidase; IFA: Incomplete Freund's adjuvant;
NPCs: Neural precursor cells; PBS: Phosphate buffered saline; pfu: Plaque forming units; SGZ: Subgranular zone; SVZ: Subventricular zone.

\section{Acknowledgements}

The authors like to thank Dr. Athanasios Lourbopoulos, currently affiliated at the Institute for Stroke and Dementia Research, Ludwig-Maximilians-University of Munich, Germany for performing immunizations. We would also like to thank the Carlos F. Barbas III laboratory, the Scripps Research Institute for

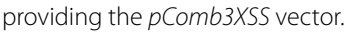

\section{Authors' contributions}

IP conducted all experiments concerning Fab library creation, biopanning, immunoblotting and immunoprecipitation. IP collected and analyzed the data, and wrote the manuscript. EK isolated neural stem cells and provided neurosphere lysates. RL,OT and MB conducted the histopathology experiments and histopathology data analysis. MS conducted mass spectrometry analysis. DD, TS and NG conceived and designed the study, interpreted the data, revised the manuscript, and had all critical supervision. All authors read and approved the final manuscript.

\section{Funding}

Not applicable.

Availability of data and materials

Please contact author for data requests.

\section{Ethics approval and consent to participate}

All experimental procedures were conducted according to the institutional guidelines, in compliance with the Greek Regulations and the European Communities Council Directive of November 24, 1986 (86/609/EEC). Experimentation received approval from the Veterinary Medicines Directorate (license number 211531/1490). Animal facility licence number EL54BIO29.

\section{Consent for publication}

Not applicable.

\section{Competing interests}

The authors declare that they have no competing interests.

\section{Author details}

${ }^{1}$ Neurodegenerative Diseases Research Group, Department of Pharmacy, School of Health Sciences, Aristotle University of Thessaloniki, 54124 Thessaloniki, Greece. ${ }^{2}$ B'Department of Neurology, AHEPA General University Hospital of Thessaloniki, Aristotle University of Thessaloniki, 54636 ThessaIoniki, Greece. ${ }^{3}$ Laboratory of Physiology, Medical School, Aristotle University of Thessaloniki, 54636 Thessaloniki, Greece. ${ }^{4}$ Biomedical Sciences Research Center'Alexander Fleming, Fleming 34, 16672 Vari, Greece. ${ }^{5}$ Department of Genetics, Development, and Molecular Biology, School of Biology, Aristotle University of Thessaloniki, 54124 Thessaloniki, Greece.

Received: 8 June 2020 Accepted: 13 July 2020

Published online: 02 August 2020

\section{References}

1. Temple $\mathrm{S}$. The development of neural stem cells. Nature. 2001;414(6859):112-7.

2. Bacigaluppi M, Sferruzza G, Butti E, Ottoboni L, Martino G. Endogenous neural precursor cells in health and disease. Brain Res. 2020;1730:146619. https://doi.org/10.1016/j.brainres.2019.146619.

3. Tang Y, Yu P, Cheng L. Current progress in the derivation and therapeutic application of neural stem cells. Cell Death Dis. 2017. https://doi. org/10.1038/cddis.2017.504.

4. Åkesson E, Piao JH, Samuelsson EB, Holmberg L, Kjældgaard A, Falci S, et al. Long-term culture and neuronal survival after intraspinal transplantation of human spinal cord-derived neurospheres. Physiol Behav. 2007;92(1-2):60-6.

5. Casarosa S, Bozzi Y, Conti L. Neural stem cells: ready for therapeutic applications? Mol Cell Ther. 2014;2(1):31. 
6. Mallett CL, Shuboni-Mulligan DD, Shapiro EM. Tracking neural progenitor cell migration in the rodent brain using magnetic resonance imaging. Front Neurosci. 2019;13:1-19.

7. Tullis GE, Spears K, Kirk MD. Immunological barriers to stem cell therapy in the central nervous system. Stem Cells Int. 2014. https://doi. org/10.1155/2014/507905.

8. Itakura G, Ozaki M, Nagoshi N, Kawabata S, Nishiyama Y, Sugai K, et al. Low immunogenicity of mouse induced pluripotent stem cell-derived neural stem/progenitor cells. Sci Rep. 2017:7(1):1-13. https://doi. org/10.1038/s41598-017-13522-W.

9. Rader C, Ritter G, Nathan S, Elia M, Gout I, Jungbluth AA, et al. The rabbit antibody repertoire as a novel source for the generation of therapeutic human antibodies. J Biol Chem. 2000;275(18):13668-76.

10. Hill J, Cave J. Targeting the vasculature to improve neural progenitor transplant survival. Transl Neurosci. 2015;6(1):162-7.

11. Barker RA, Widner $\mathrm{H}$. Immune problems in central nervous system cell therapy. NeuroRx. 2004;1 (4):472-81.

12. Kesidou E, Touloumi O, Lagoudaki R, Nousiopoulou E, Theotokis $P$, Poulatsidou KN, et al. Humoral response in experimental autoimmune encephalomyelitis targets neural precursor cells in the central nervous system of naive rodents. J Neuroinflamm. 2017;14(1):1-14.

13. Shen $Y$, Yang $X$, Dong N, Xie X, Bai X, Shi Y. Generation and selection of immunized Fab phage display library against human B cell lymphoma. Cell Res. 2007;17(7):650-60.

14. Mueller NH, Graf LL, Shearer AJ, Owens GP, Gilden DH, Cohrs RJ. Construction of recombinant mouse $\operatorname{lgG} 1$ antibody directed against varicella zoster virus immediate early protein 63. Hybridoma (Larchmt). 2008;27(1):1-10.

15. Kulmala A, Huovinen T, Lamminmäki U. Effect of DNA sequence of Fab fragment on yield characteristics and cell growth of E. coli. Sci Rep. 2017:7(1):1-10.

16. Barbas CF, Crowe JE, Cababa D, Jones TM, Zebedee SL, Murphy BR, et al. Human monoclonal Fab fragments derived from a combinatorial library bind to respiratory syncytial virus F glycoprotein and neutralize infectivity. Proc Natl Acad Sci USA. 1992;89(21):10164-8.

17. Dimitrov JD, Planchais C, Roumenina LT, Vassilev TL, Kaveri SV, LacroixDesmazes S. Antibody polyreactivity in health and disease: statu variabilis. J Immunol. 2013;191(3):993-9.
18. Biagioli M, Pinto M, Cesselli D, Zaninello M, Lazarevic D, Roncaglia P, et al. Unexpected expression of $a-$ and $\beta$-globin in mesencephalic dopaminergic neurons and glial cells. PNAS. 2009;106(36):15454-9.

19. Zhou Y, Goenaga AL, Harms BD, Zou H, Lou J, Conrad F, et al. Impact of intrinsic affinity on functional binding and biological activity of EGFR antibodies. Mol Cancer Ther. 2012;11(7):1467-76.

20. Barbas CF III, Burton DR, Scott GJS. Phage display: a laboratory manual. Cold Spring Harbor: Cold Spring Harbor Laboratory Press; 2001.

21. Bugli F, Sterbini FP, Graffeo R, Caridi F, lantomasi R, Torelli R, et al. Effective use of nitrocellulose-blotted antigens for phage display monoclonal antibody selection. New Microbiol. 2011;34(3):281-6.

22. Brochet $X$, Lefranc MP, Giudicelli V. IMGTN-QUEST: the highly customized and integrated system for IG and TR standardized $V$-J and V-D-J sequence analysis. Nucleic Acids Res. 2008;36(Web Server issue):503-8.

23. Ye J, Ma N, Madden TL, Ostell JM. IgBLAST: an immunoglobulin variable domain sequence analysis tool. Nucleic Acids Res. 2013;41(Web Server issue):34-40.

24. Laemmli UK. Cleavage of structural proteins during the assembly of the head of bacteriophage T4. Nature. 1970;227(5259):680-5.

25. Schneider CA, Rasband WS, Eliceiri KW. NIH Image to ImageJ: 25 years of image analysis. Nat Methods. 2012;9(7):671-5. https://doi.org/10.1038/ nmeth.2089.

26. Polymenidou M, Verghese-Nikolakaki S, Groschup M, Chaplin MJ, Stack MJ, Plaitakis A, et al. A short purification process for quantitative isolation of PrPSC from naturally occurring and experimental transmissible spongiform encephalopathies. BMC Infect Dis. 2002;2:23.

27. Shevchenko A, Tomas H, Havlis J, Olsen JV, Mann M. In-gel digestion for mass spectrometric characterization of proteins and proteomes. Nat Protoc. 2006;1(6):2856-60.

\section{Publisher's Note}

Springer Nature remains neutral with regard to jurisdictional claims in published maps and institutional affiliations.
Ready to submit your research? Choose BMC and benefit from:

- fast, convenient online submission

- thorough peer review by experienced researchers in your field

- rapid publication on acceptance

- support for research data, including large and complex data types

- gold Open Access which fosters wider collaboration and increased citations

- maximum visibility for your research: over $100 \mathrm{M}$ website views per year

At $\mathrm{BMC}$, research is always in progress.

Learn more biomedcentral.com/submissions 